\title{
Au(I)-Catalyzed Pictet-Spengler Reactions: a Journey Around the Indole Ring
}

Pierre Milcendeau, ${ }^{a}$ Zhenhao Zhang, ${ }^{a, b}$ Nicolas Glinsky-Olivier, ${ }^{a}$ Elsa van Elslande ${ }^{a}$ and Xavier Guinchard*a $^{* a}$

a Université Paris-Saclay, CNRS, Institut de Chimie des Substances Naturelles, UPR 2301, 91198, Gif-sur-Yvette, France.

${ }^{\mathrm{b}}$ LCM, CNRS, Ecole Polytechnique, Institut Polytechnique de Paris, 91128 Palaiseau, France.
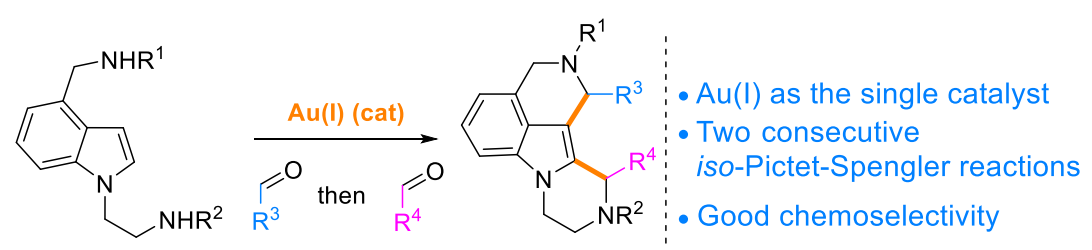

$\mathrm{Au}(\mathrm{I})$ complexes catalyze iso-Pictet-Spengler reactions. Ethylamine or methylamine chains were introduced at C2, $\mathrm{C4}$ or at the nitrogen atom of the indole ring, and the corresponding substrates were reacted in the presence of aldehydes and catalytic amounts of Au(I) complexes, leading to a variety of polycyclic scaffolds. Selectivity could be achieved in the course of a double iso-Pictet-Spengler reaction involving two successive aldehydes, leading to highly complex molecules.

Indole alkaloids are major heterocycles because of their prevalence natural and bioactive compounds. ${ }^{1}$ Among the privileged scaffolds, tetrahydro- $\beta$-carbolines 1 are important molecules and their structural unit is embedded in numerous natural products, among which a huge number are bioactive. ${ }^{2}$ The Pictet-Spengler reaction ${ }^{3,4}$ com- $^{-}$ bining tryptamines and aldehydes is unarguably the easiest and fastest way to prepare such scaffolds. ${ }^{2 b}$ Rich of more than a century of research, this reaction and its mechanism has been intensively studied ${ }^{5}$ and applied to numerous total syntheses. ${ }^{2 \mathrm{~b}}$ Interestingly, because of the nucleophilicity of indole at $\mathrm{C} 2$ and $\mathrm{C} 3,{ }^{6}$ numerous variants of this reaction lead to structurally related compounds, such as 1,2,3,4-tetrahydropyrazino[1,2-a]indoles 2, ${ }^{7}$ tetrahydro- $\gamma$-carbolines $3,{ }^{8}$ and 1,3,4,5-tetrahydropyrrolo[4,3,2-de] isoquinoline $4{ }^{7 b}, 9$ (Figure 1). These so-called iso-Pictet-Spengler reactions are far less studied than the venerable historic reaction, despite allowing access to interesting heterocycles.

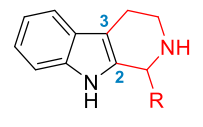

tetrahydro- $\beta$-carbolines 1

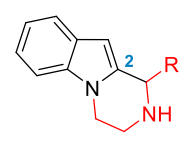

1,2,3,4-tetrahydropyrazino [1,2-a]indoles 2

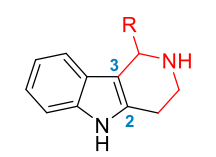

tetrahydro- $\gamma$-carbolines 3

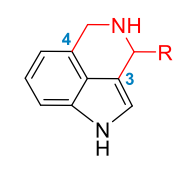

1,3,4,5-tetrahydropyrrolo [4,3,2-de]isoquinolines 4

Figure 1. Tetrahydro- $\beta$-carbolines and regioisomeric congeners 
Our group has long been interested in gold-catalyzed reactions ${ }^{10}$ involving indolic compounds, in particular the functionalization of indoles with alkynes. ${ }^{11,12}$ Recently, we discovered that Pictet-Spengler reactions could be catalyzed by $\mathrm{Au}(\mathrm{I})$ complexes $^{13,14}$ (Scheme 1, eq. 1). These reactions occur via a mechanism involving the auration of the indole ring that we established through both experimental and computational studies. We hypothesized that similar reactions catalyzed by $\mathrm{Au}(\mathrm{I})$ complexes should occur from the use of other regioisomeric alkylamines $\mathbf{5}$. Herein, we show that it is possible to obtain regioisomeric compounds $\mathbf{2 ,} \mathbf{3}$ and $\mathbf{4}$ from gold-catalyzed iso-PictetSpengler reactions (Scheme 1, eq. 2).

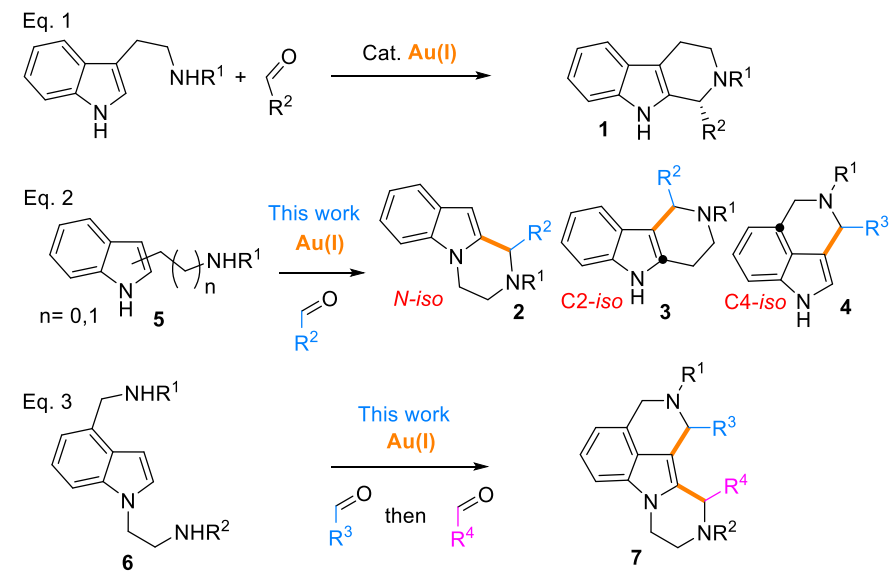

Scheme 1. Context of this work

For clarity purpose, we defined those reactions as $\mathrm{N}$-iso-, $\mathrm{C2}$-iso- and $\mathrm{C} 4-$ iso-Pictet-Spengler reactions, depending on the connecting atom of the indole ring to the alkylamine chain. With a good knowledge of each of these different versions of the reaction, we could achieve a one-pot, selective process including successively a C4-iso and a $\mathrm{N}$-iso-Pictet-Spengler reaction for the synthesis of complex compounds $\mathbf{7}$ via the $\mathrm{C} 3$ then $\mathrm{C} 2$ ring-closures, with two different aldehdyes (Scheme 1, eq. 3).

Our journey started with the study of the $\mathrm{N}$-iso-Pictet-Spengler reactions from $\mathrm{N}$-iso-tryptamine $\mathbf{5 a}$ and benzaldehyde $\mathbf{8 a}$, reacted in toluene in the presence of molecular sieves over a $40 \mathrm{~h}$ period (Table 1 ). In the absence of catalyst, no background reaction occurred (entry 1). Though counterintuitive, the reaction did not proceed either in the presence of an acidic catalyst, as previously reported ${ }^{7 e}$ for C3-unsubstituted $\mathrm{N}$-iso-tryptamines (entry 2). ${ }^{15}$ We next screened a series of three $\mathrm{Au}(\mathrm{I})$ catalysts (entries 3-5), for which only the Gagosz catalyst ${ }^{16}$ led to a moderate conversion ( $20 \%$, entry 4$)$. The solvent was replaced by DCM, allowing to reach a $69 \%$ conversion, further optimized to $74 \%$ after slight increase of the reaction temperature (entries 6-7). 
Table 1. Optimisation of the $N$-iso Pictet-Spengler reaction

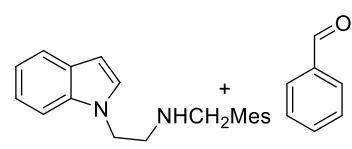

5a

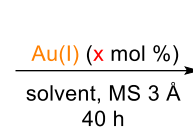

$40 \mathrm{~h}$

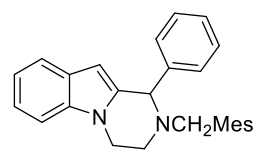

$2 a$

\begin{tabular}{ccccc}
\hline entry & Catalyst (mol\%) & Solvent & $\mathrm{T}\left({ }^{\circ} \mathrm{C}\right)$ & Conv $(\%)^{\mathrm{a}}$ \\
\hline 1 & - & $\mathrm{PhMe}_{\mathrm{DCM}}$ or & $\mathrm{rt}$ & 0 \\
2 & $(\mathrm{PhO})_{2} \mathrm{POOH}(5)$ & $\mathrm{PhMe}$ & $\mathrm{rt}$ & 0 \\
3 & Cat a (5) & PhMe & $\mathrm{rt}$ & 0 \\
4 & Cat b (5) & PhMe & $\mathrm{rt}$ & 20 \\
5 & Cat c (5) & PhMe & $\mathrm{rt}$ & Traces \\
6 & Cat b (5) & DCM & $\mathrm{rt}$ & 69 \\
7 & Cat b (5) & DCM & 30 & 74
\end{tabular}

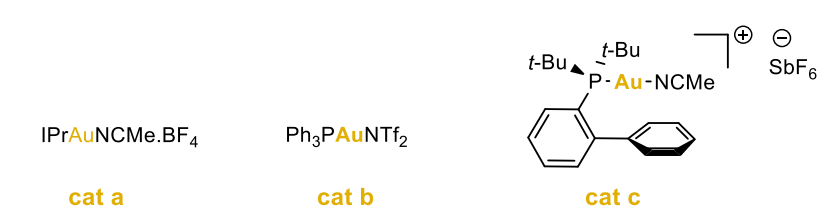

${ }^{a}$ Conversion were measured by ${ }^{1} \mathrm{H}$ NMR.

We next engaged a number of aromatic aldehydes in the reaction (Scheme 2, $\mathrm{N}$-iso Pictet-Spengler reaction). The reactions performed with benzaldehyde and $p$-bromobenzaldehyde led to $\mathbf{2 a}$ and $\mathbf{2} \mathbf{b}$ in $87 \%$ and $51 \%$ yields, respectively. A bromide group was tolerated at the meta and para positions, leading to compounds $\mathbf{2 c}$ and $\mathbf{2 d}$ in good yields. The reaction also proved compatible with aldehydes bearing electron-withdrawing $\mathrm{CF}_{3}$ groups at the para and meta positions. When $m$-methoxybenzaldehyde $\mathbf{8 g}$ was used, the corresponding product $\mathbf{2 g}$ was obtained in 59\% yield. 4- and 6-quinoline carbaldehydes then furnished compounds $\mathbf{2} \mathbf{h}$ and $\mathbf{2} \mathbf{i}$ in $87 \%$ and $93 \%$ yields, respectively. However, the reaction showed a complete selectivity towards aromatic aldehydes, since 3-phenylpropanal did not lead to the expected compounds $\mathbf{2} \mathbf{j}$.

We switched to the gold-catalyzed C2-iso-Pictet-Spengler reaction, performed from isotryptamine $\mathbf{5 b}$ and a range of aldehydes (Scheme 2, C2-iso Pictet-Spengler reaction). Of note, this reaction is characterized by a strong background reaction that can be suppressed by decreasing the temperature to $-20{ }^{\circ} \mathrm{C}$. At this temperature, the tetrahydro- $\gamma$-carboline $3 a$ was obtained in $54 \%$ yield when the reaction was performed in the presence of complex $\mathbf{b}$ (5 mol\%), testifying for a solely $\mathrm{Au}(\mathrm{I})$-catalyzed process. We screened a selection of functionalized arylaldehydes that could potentially result in reactivity issues if the reaction was acid-catalyzed. Compounds $\mathbf{3 b}$ and $\mathbf{3 c}$ bearing a 4-quinolynyl and 4-pyridyl chain, respectively, were obtained in good yields. Isophthalaldehyde led to the product $\mathbf{3 d}$ in $\mathbf{7 5 \%}$ yield as a single product (no trace of doubly functionalized compound). Remarkably, despite a lower conversion, the reaction also tolerated an aldehyde bearing a nitrone function, yet known to be activated by $\mathrm{Au}(\mathrm{I})$ complexes, ${ }^{17}$ leading to compound $3 \mathrm{e}$ in $47 \%$ yield. ${ }^{18}$ Comparatively, this kind of aldehyde would not be suitable in related acidic-catalyzed reactions, because of the activation of the highly electrophilic nitrone.

We further moved toward the introduction of the alkylamine chain at C4 atom of the indole ring (Scheme 2, C4iso Pictet-Spengler reaction). The reaction of $\mathbf{5 c}$ with $p$-bromobenzaldehyde in DCM at room temperature in the presence of only 2 mol\% of Gagosz catalyst led to the corresponding 1,3,4,5-tetrahydropyrrolo[4,3,2-de]isoquinoline $\mathbf{4 a}$ in $75 \% .{ }^{19}$ Benzaldehyde and $m$-trifluoromethylbenzaldehyde also led to excellent yields in $\mathbf{4 b}, \mathbf{c}$. A fluorine group at the ortho position was well tolerated, while a methoxy group at the para position led to a decrease of 
the reactivity ( $4 \mathrm{e}, 38 \%$ yield). The phthalaldehyde led to compound $\mathbf{4 f}$ in $46 \%$ yield, this time accompanied by the dimeric product (ratio $\mathbf{4 f} /$ dimer: 10/4). A boronate ester at the para position was tolerated, leading to $\mathbf{4 g}$ in $53 \%$ yield, opening opportunities for subsequent cross-coupling functionnalizations. $4 \mathrm{~h}$, bearing a quinolyl moiety was formed in $\mathbf{7 1 \%}$ yield. Interestingly, aliphatic aldehydes were well converted to compounds $\mathbf{4 i - \mathbf { k }}$ in moderate to good yields. To date, this is the first time that we observed conversion in the course of any version of the four different $\mathrm{Au}(\mathrm{I})$-catalyzed (iso)Pictet-Spengler reactions that we studied involving aliphatic aldehydes.

We next considered the possibility that an indole ring functionalized with two alkylamine chains at the $\mathrm{N}$ - and C4position could undergo $\mathrm{C2}-\mathrm{C} 3$ difunctionalization via a $\mathrm{C} 4$-iso and a $\mathrm{N}$-iso-Pictet-Spengler cyclization cascade. For this purpose, we designed the diamine $\mathbf{5 d}$, keeping the same groups on the nitrogen atoms. Indeed, gold-catalyzed reaction of $\mathbf{5} \mathbf{d}$ with benzaldehyde at $30^{\circ} \mathrm{C}$ led to tetracyclic $2,3,8,9,10,11$-hexahydro- $1 \mathrm{H}$-pyrazino[1',2':1,5]pyrrolo[4,3,2-de]isoquinoline $9 \mathrm{a}$ in $68 \%$ yield and a 70/30 diatereomeric ratio, in favor of the anti diastereoisomer (Scheme 3). ${ }^{20}$
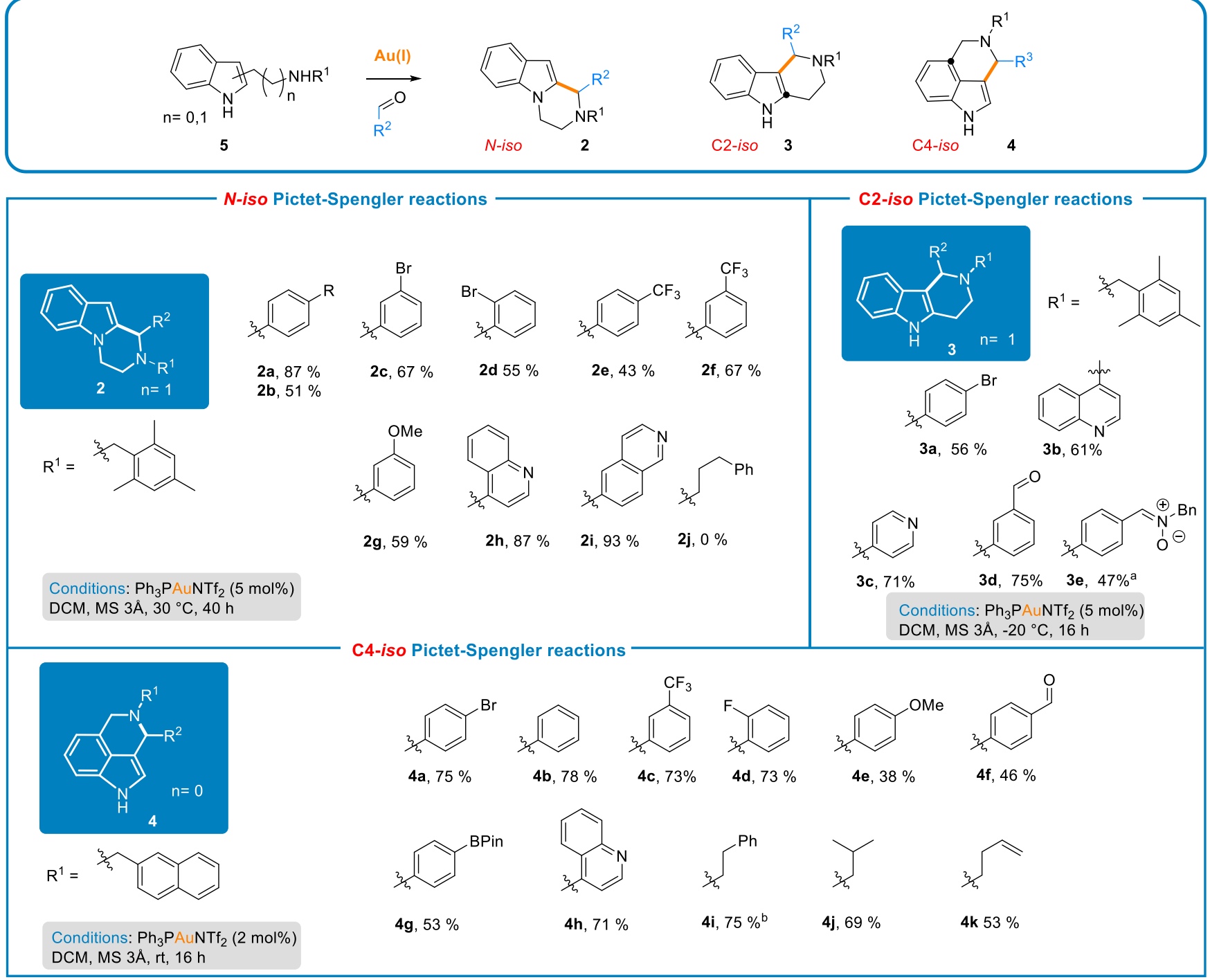

a Performed at rt. ${ }^{b}$ Performed with 5 mol\% of $\mathrm{Ph}_{3} \mathrm{PAuNTf}_{2}$.

Scheme 2. Scope of the different versions of the iso-Pictet-Spengler reactions studied 


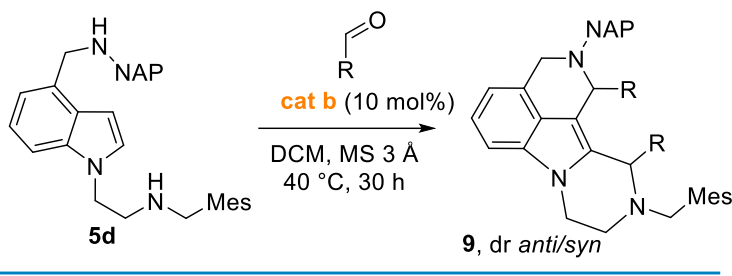

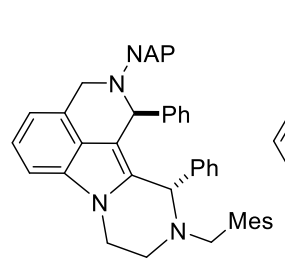

9a, $\mathrm{dr} 70 / 30,68 \%$

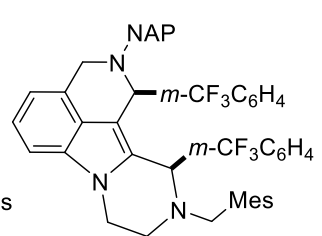

$9 b$, dr $20 / 80,58 \%$

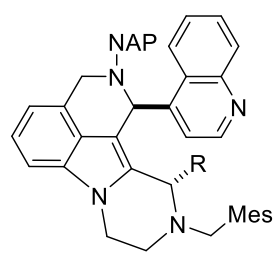

9c, dr $100 / 0,88 \%$ $\mathrm{R}=4$-quinolyl

Scheme 3. $\mathrm{C} 4 / \mathrm{N}$-iso-Pictet-Spengler reactions combined (the related stereochemistry indicated is that of the major diastereomer)

To the best of our knowledge, this scaffold has never been reported. When the meta-trifluoromethylbenzaldehyde was used, compound $\mathbf{9 b}$ was obtained in $58 \%$ yield, with the diasteromeric ratio in favor of the syn isomer. 4Quinoline carboxaldehyde led to the amine $9 \mathrm{c}$ in $88 \%$ yield and full anti-diastereoselectivity.

We next reasoned that the C4-iso Pictet-Spengler reaction, operating with lower catalyst loading and temperature, should occur faster than the $\mathrm{N}$-iso reaction, requiring higher catalyst loading and temperature. Indeed, when $\mathbf{5 d}$ was engaged in the reaction with 1 equivalent of $p$-bromobenzaldehyde, the C4-iso Pictet-Spengler product 10a was selectively obtained at room temperature in $71 \%$ yield (Scheme 4 , eq. 1 ). It was then engaged in the $\mathrm{N}$-iso Pictet-Spengler reaction with benzaldehyde that led to 11 a in $70 \%$ yield as a mixture of diastereomers (Scheme 4, eq. 2 , dr 25/75).

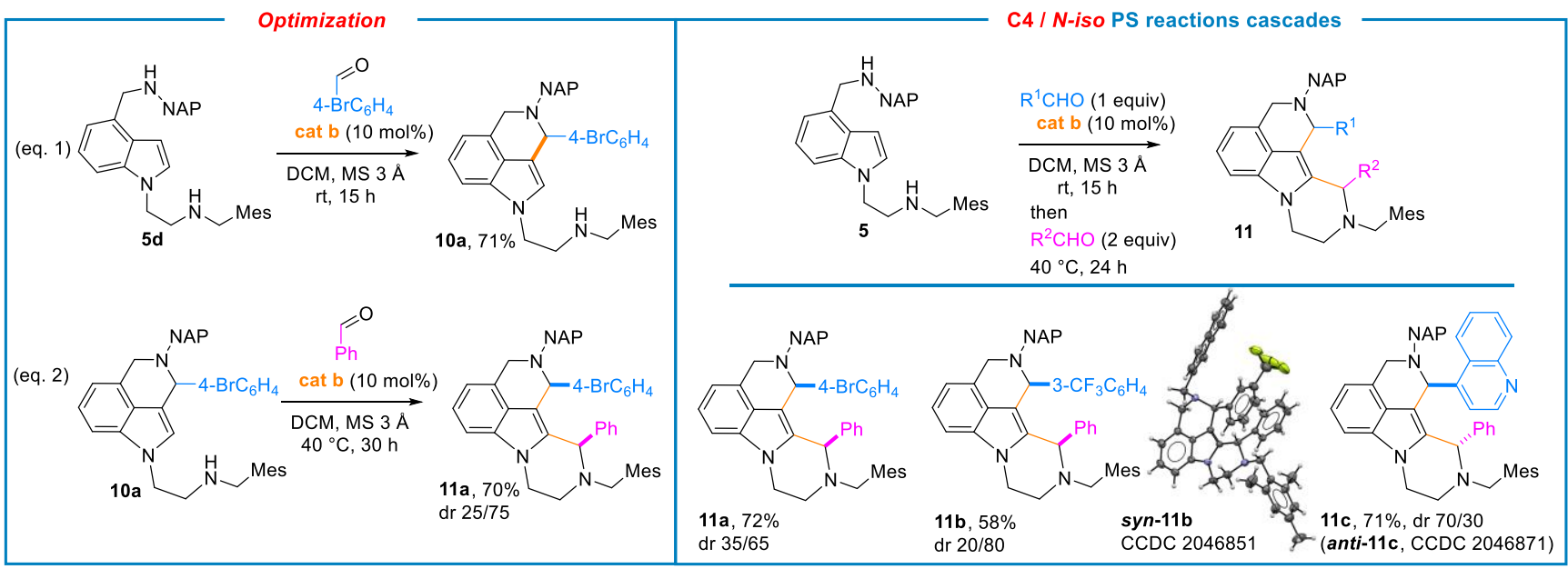

Scheme 4. Selective bis-functionnalization (the relative stereochemistry indicated is that of the major diastereomer)

We then developed the one-pot formation of compounds 11 by sequential addition of two different aldehydes from $\mathbf{5 d}$ in the presence of 10 mol\% of the gold complex $\mathbf{b}$ as catalyst (Scheme 4, right part). After $15 \mathrm{~h}$ of reaction in the presence of $p$-bromobenzaldehyde (1 equiv) at room temperature, benzaldehyde was added to the reaction mixture and further $24 \mathrm{~h}$ reaction led to compound $11 \mathrm{a}$ in $72 \%$ yield ( $\mathrm{dr} 35 / 65$ ) in favor of the syn isomer. The same protocol was applied to another couple of aromatic aldehydes, leading to compound $\mathbf{1 1} \mathbf{b}$ in good yields and good diastereoselectivity ( $\mathrm{dr}$ 20/80). Gratifyingly, we obtained the Xray structure of the syn-diastereomer of $\mathbf{1 1 b}$. Beyond confirming its structure, it was helpful to further identify all other diastereomers of the series of compounds 9 and 11. When 4-quinolinecarboxaldehyde was used in the first C4-iso-Pictet-Spengler step (requiring a 
higher $40^{\circ} \mathrm{C}$ temperature), followed by benzaldehyde for the $\mathrm{N}$-iso step, compound $11 \mathrm{c}$ was obtained in $71 \%$ yield and diastereoselectivity in favor of the anti-isomer. The diastereoselectivity of these reactions may be the result of electronic effects. Indeed, the Xray structure of the syn-11b shows a pretty good superposition of the phenyl and the trifluoromethylphenyl ring with a distance between the two aryl planes of ca. 3.30 Ả. As reviewed by Iverson, interactions between electron-poor/electron rich aryls may be referred to the favored "aromatic donoracceptor interactions" or polar/ $\pi$ model. ${ }^{21}$ This would explain the general trend to lead to the syn-diastereomer with electron-poor aryl (9b, 11a, 11b) while destabilizing interactions operating with electron-rich aryl rings couples (phenyl, quinoline and their combination) lead mainly to the anti-isomer (9a, 9c, 11c).

Gratifyingly, no need for an addition batch of catalyst was required for the application of this protocol. The formation of these compounds, as the result of two successive iso-Pictet-Spengler reactions with different aldehydes, opens avenues for the synthesis of highly functionalized and complex compounds. This strategy potentially offers unique opportunities for the exploration of chemical space in biological studies.

The mechanistic hypothesis for these reactions relies on our previous gold-catalyzed "classical" Pictet-Spengler reactions ${ }^{13 a}$ and is illustrated below with the $\mathrm{N}$-iso-version of the reaction (Scheme 5), with the following steps. (i) The spontaneous addition of the amine to the aldehyde leads to an hemiaminal (this step being potentially catalyzed by the $A u(I)$ complex). (ii) The coordination of the indole ring leads to the $\eta^{2}$ and $\eta^{1}$-gold complexes $\mathbf{A}$ and $\mathbf{B}$. (iii) The conversion of the latter to an iminium via an intramolecular abstraction of a proton and release of water generates $\mathbf{C}$. (iv) the nucleophilic addition to the iminium via $\mathrm{C} 2$ forms complexO $\mathbf{D}$. ( $v$ ) The elimination of a proton $v i a \mathbf{E}$ and protodeauration then leads to the product $\mathbf{2}$ and the regeneration of the cationic $A u(I)$ complex. Similar mechanisms can be involved for the C2- and C4-iso-Pictet-Spengler reactions (see the supporting Information).

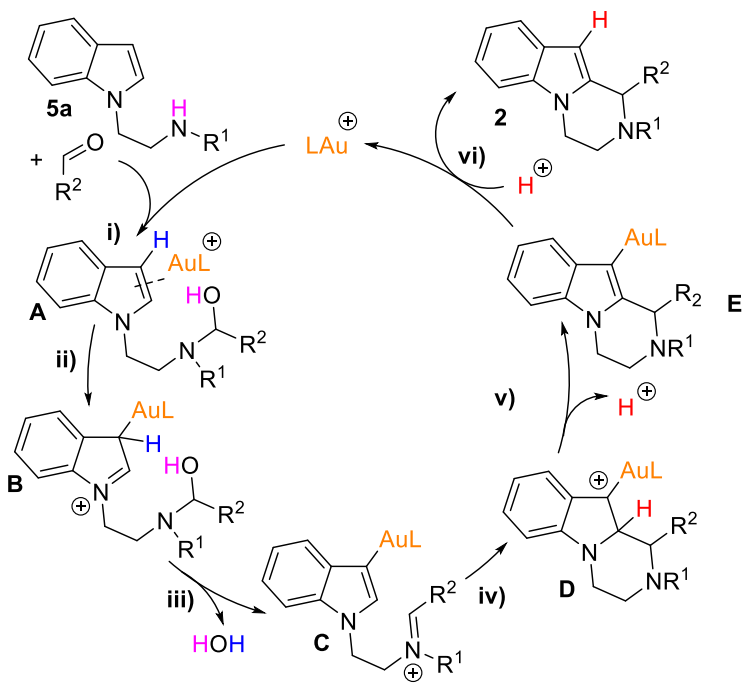

Scheme 5. Mechanistic pathway in N-iso-Pictet-Spengler reactions

To conclude, we have developed $\mathrm{Au}(\mathrm{I})$-catalyzed iso-Pictet-Spengler reactions by introduction of the alkylamine chain around all the different positions of the indole ring allowing a trapping of the in situ generated iminium ion by either the $\mathrm{C} 2$ or $\mathrm{C} 3$ atom. This led to the isolation of numerous heterocyclic scaffolds. We have showed the high chemoselectivity enabled by $\mathrm{Au}(\mathrm{I})$ catalyzed processes in these reactions, in particular by design of the in situ sequential cascade of $\mathrm{C} 4$ - and $\mathrm{N}$-iso-Pictet-Spengler reactions leading to highly complex polycyclic indolic arrangements.

Corresponding Author : Xavier Guinchard: xavier.guinchard@cnrs.fr 
Author Contributions: All authors have given approval to the final version of the manuscript.

Acknowledgements: Pierre Milcendeau and Nicolas Glinsky-Olivier thank MESRI (Paris-Saclay University) for a PhD fellowship and the CHARMMMAT Laboratory of Excellence (ANR-11-LABX0039) for financial support. Zhenhao Zhang thanks the China Scholarship Council for PhD funding.

\section{References}

(1) (a) Rahman, A.; Basha, A., Indole Alkaloids. Harwood accademic publishers: Reading, Berks, 1999. (b) Kawasaki, T.; Higuchi, K. Nat. Prod. Rep. 2005, 22, 761-793. (c) Gul, W.; Hamann, M. T. Life Sciences 2005, 78, 442-453. (d) O'Connor, S. E.; Maresh, J. J. Nat. Prod. Rep. 2006, 23, 532-547.

(2) (a) Maity, P.; Adhikari, D.; Jana, A. K. Tetrahedron 2019, 75, 965-1028. (b) Glinsky-Olivier, N.; Guinchard, X. Synthesis 2017, 49, 2605-2620. (c) Cao, R.; Peng, W.; Wang, Z.; Xu, A. Curr. Med. Chem. 2007, 14, 479-500.

(3) (a) Pictet, A.; Spengler, T. Ber. Dtsch. Chem. Ges. 1911, 44, 2030-2036. (b) Tatsui, G. Yakugaku Zasshi 1928, 48, 453-459.

(4) (a) Calcaterra, A.; Mangiardi, L.; Delle Monache, G.; Quaglio, D.; Balducci, S.; Berardozzi, S.; lazzetti, A.; Franzini, R.; Botta, B.; Ghirga, F. Molecules 2020, 25. (b) Gholamzadeh, P., Chapter Three - The Pictet-Spengler Reaction: A Powerful Strategy for the Synthesis of Heterocycles. In Advances in Heterocyclic Chemistry, Scriven, E. F. V.; Ramsden, C. A., Eds. Academic Press: 2019; Vol. 127, pp 153-226. (c) Rao, R. N.; Maiti, B.; Chanda, K. ACS Comb. Sci. 2017, 19, 199-228. (d) Ingallina, C.; D'Acquarica, I.; Delle Monache, G.; Ghirga, F.; Quaglio, D.; Ghirga, P.; Berardozzi, S.; Markovic, V.; Botta, B. Curr. Pharm. Des. 2016, 22, 1808-1850. (e) Dalpozzo, R. Molecules 2016, 21, 699. (f) Bijoy, K.; Piyush, K. A.; Sudhir, K. S.; Devesh, S.; Anil, K. M.; Mohammad, S.; Sahaj, G. Curr. Org. Synth. 2012, 9, 357-376. (g) Stockigt, J.; Antonchick, A. P.; Wu, F. R.; Waldmann, H. Angew. Chem. Int. Ed. 2011, 50, 8538-8564. (h) Lorenz, M.; Van Linn, M. L.; Cook, J. M. Curr. Org. Synth. 2010, 7, 189-223. (i) Cox, E. D.; Cook, J. M. Chem. Rev. 1995, 95, 1797-1842.

(5) (a) Zheng, C.; You, S.-L. Acc. Chem. Res. 2020, 53, 974-987. (b) Zheng, C.; Xia, Z.-L.; You, S.-L. Chem 2018, 4, 1952-1966. (c) Unsworth, W. P. Chem 2018, 4, 1767-1770. (d) Kowalski, P.; Mokrosz, J. L. Bull. Chem. Soc. Belg. 1997, 106, 147-149. (e) Kowalski, P.; Bojarski, A. J.; Mokrosz, J. L. Tetrahedron 1995, 51, 2737-2742. (f) Bailey, P. D. J. Chem. Res. 1987, 202-203. (g) Bailey, P. D. Tetrahedron Lett. 1987, 28, 5181-5184. (h) Soerens, D.; Sandrin, J.; Ungemach, F.; Mokry, P.; Wu, G. S.; Yamanaka, E.; Hutchins, L.; Dipierro, M.; Cook, J. M. J. Org. Chem. 1979, 44, 535-545. (i) Gobé, V.; Gandon, V.; Guinchard, X. Adv. Synth. Catal. 2018, 360, 1280-1288.

(6) Lakhdar, S.; Westermaier, M.; Terrier, F.; Goumont, R.; Boubaker, T.; Ofial, A. R.; Mayr, H. J. Org. Chem. 2006, 71, 9088-9095.

(7) (a) Wu, F.; Zhu, H.; Sun, L.; Rajendran, C.; Wang, M.; Ren, X.; Panjikar, S.; Cherkasov, A.; Zou, H.; Stöckigt, J. J. Am. Chem. Soc. 2012, 134, 1498-1500. (b) Schönherr, H.; Leighton, J. L. Org. Lett. 2012, 14, 2610-2613. (c) Bhanushali, M. J.; Nandurkar, N. S.; Bhor, M. D.; Bhanage, B. M. Tetrahedron Lett. 2007, 48, 1273-1276. (d) Tiwari, R. K.; Verma, A. K.; Chhillar, A. K.; Singh, D.; Singh, J.; Kasi Sankar, V.; Yadav, V.; Sharma, G. L.; Chandra, R. Bioorg. Med. Chem. 2006, 14, 2747-2752. (e) Tiwari, R. K.; Singh, J.; Singh, D.; Verma, A. K.; Chandra, R. Tetrahedron 2005, 61, 9513-9518. (f) Katritzky, A. R.; Verma, A. K.; He, H.-Y.; Chandra, R. J. Org. Chem. 2003, 68, 4938-4940.

(8) (a) Voznesenskaia, N. G.; Shmatova, O. I.; Nenajdenko, V. G. Synthesis 2020, 52, 263-272. (b) Zhai, F.; Jordan, R. F. Inorg. Chim. Acta 2018, 482, 491-496. (c) Urmode, T. D.; Dawange, M. A.; Shinde, V. S.; Kusurkar, R. S. Tetrahedron 2017, 73, 4348-4354. (d) Riesco-Domínguez, A.; van der Zwaluw, N.; Blanco-Ania, D.; Rutjes, F. P. J. T. Eur. J. Org. Chem. 2017, 2017, 662-670. (e) Huang, L.; Dai, L.-X.; You, S.-L. J. Am. Chem. Soc. 2016, 138, 57935796. (f) Li, X.; Chen, D.; Gu, H.; Lin, X. Chem. Commun. 2014, 50, 7538-7541. (g) Lee, Y.; Klausen, R. S.; Jacobsen, E. N. Org. Lett. 2011, 13, 5564-5567. (h) Grigg, R.; Sridharan, V.; Sykes, D. A. Tetrahedron 2008, 64, 8952-8962.

(9) Patil, N. T.; Shinde, V. S.; Sridhar, B. Angew. Chem. Int. Ed. 2013, 52, 2251-2255.

(10) (a) Cera, G.; Bandini, M. Isr. J. Chem. 2013, 53, 848-855. (b) Obradors, C.; Echavarren, A. M. Acc. Chem. Res. 2014, 47, 902-912. (c) Zi, W.; Toste, D. F. Chem. Soc. Rev. 2016, 45, 4567-4589. (d) Ranieri, B.; Escofet, I.; Echavarren, A. M. Org. Biomol. Chem. 2015, 13, 7103-7118. (e) Dorel, R.; Echavarren, A. M. Chem. Rev. 2015, 115, 9028-9072. (f) Mascareñas, J. L.; Varela, I.; López, F. Acc. Chem. Res. 2019, 52, 465-479.

(11) (a) Pirovano, V. Eur. J. Org. Chem. 2018, 2018, 1925-1945. (b) Milcendeau, P.; Sabat, N.; Ferry, A.; Guinchard, X. Org. Biomol. Chem. 2020, 18, 6006-6017. 
(12) (a) Gobé, V.; Dousset, M.; Retailleau, P.; Gandon, V.; Guinchard, X. Adv. Synth. Catal. 2016, 358, 3960-3965.

(b) Magné, V.; Blanchard, F.; Marinetti, A.; Voituriez, A.; Guinchard, X. Adv. Synth. Catal. 2016, 358, 3355 - 3361.

(c) Magné, V.; Marinetti, A.; Gandon, V.; Voituriez, A.; Guinchard, X. Adv. Synth. Catal. 2017, 359, 4036-4042. (d)

Magné, V.; Retailleau, P.; Marinetti, A.; Voituriez, A.; Guinchard, X. Molbank 2018, M985. (e) Gobé, V.; Dousset, M.; Retailleau, P.; Gandon, V.; Guinchard, X. J. Org. Chem. 2018, 83, 898-912. (f) Glinsky-Olivier, N.; Retailleau, P.; Guinchard, X. Eur. J. Org. Chem. 2018, 2018, 5823-5829. (g) Zhang, Z.; Smal, V.; Retailleau, P.; Voituriez, A.; Frison, G.; Marinetti, A.; Guinchard, X. J. Am. Chem. Soc. 2020, 142, 3797-3805. (h) Sabat, N.; Soualmia, F.; Retailleau, P.; Benjdia, A.; Berteau, O.; Guinchard, X. Org. Lett. 2020, 22, 4344-4349. (i) Magné, V.; Sanogo, Y.; Demmer, C. S.; Retailleau, P.; Marinetti, A.; Guinchard, X.; Voituriez, A. ACS Catal. 2020, 10, 8141-8148.

(13) (a) Glinsky-Olivier, N.; Yang, S.; Retailleau, P.; Gandon, V.; Guinchard, X. Org. Lett. 2019, 21, 9446-9451. (b) Gobé, V.; Retailleau, P.; Guinchard, X. Chem. Eur. J. 2015, 21, 17587-17590.

(14) (a) Youn, S. W. J. Org. Chem. 2006, 71, 2521-2523. (b) Subba Reddy, B. V.; Swain, M.; Reddy, S. M.; Yadav, J. S.; Sridhar, B. J. Org. Chem. 2012, 77, 11355-11361.

(15) The same isotryptamine protected with a benzyl group on the amine function however reacts in this reaction in the presence of acid. The methylenemesityl group that we have used here, as in our previous study (see ref $13 a)$, allows to guarantee a purely gold-catalyzed reaction.

(16) Mézailles, N.; Ricard, L.; Gagosz, F. Org. Lett. 2005, 7, 4133-4136.

(17) (a) Jónsson, H. F.; Fiksdahl, A. Dalton Trans. 2019, 48, 142-149. (b) Jónsson, H. F.; Evjen, S.; Fiksdahl, A. Org. Lett. 2017, 19, 2202. (c) Evjen, S.; Fiksdahl, A. Tetrahedron 2016, 72, 3270-3276.

(18) The conversion rate was $65 \%$. The same reaction without catalyst led to a lower $25 \%$ conversion over $60 \mathrm{~h}$.

(19) The conversion was $77 \%$ after $7.5 \mathrm{~h}$ ( 5 mol\% catalyst). The same reaction in the absence of catalyst lead to $8 \%$ conversion. See the Supporting Information.

(20) Both syn and anti diastereomers of the series have a typical footprint in ${ }^{1} \mathrm{H}$ NMR spectra. NOESY experiments and XRay obtained in other compounds of the series allowed the determination of the relative configurations of all the products by analogy.

(21) (a) Martinez, C. R.; Iverson, B. L. Chem. Sci. 2012, 3, 2191-2201. (b) Cozzi, F.; Ponzini, F.; Annunziata, R.; Cinquini, M.; Siegel, J. S. Angew. Chem. Int. Ed. 1995, 34, 1019-1020. (c) Hunter, C. A.; Sanders, J. K. M. J. Am. Chem. Soc. 1990, 112, 5525-5534. (d) Wheeler, S. E.; Houk, K. N. J. Am. Chem. Soc. 2008, 130, 10854-10855. 